\title{
Grapefruit-medication interactions: Forbidden fruit or avoidable consequences?
}

\author{
David G. Bailey BScPhm PhD, George Dresser MD PhD, J. Malcolm O. Arnold MB BCh MD
}

$\mathrm{O}$ ur research group discovered the interaction between grapefruit and certain medications more than 20 years ago. ${ }^{1-3}$ Currently, more than 85 drugs, most of which are available in Canada, are known or predicted to interact with grapefruit. This interaction enhances systemic drug concentration through impaired drug metabolism.

Many of the drugs that interact with grapefruit are highly prescribed and are essential for the treatment of important or common medical conditions. Recently, however, a disturbing trend has been seen. Between 2008 and 2012, the number of medications with the potential to interact with grapefruit and cause serious adverse effects (i.e., torsade de pointes, rhabdomyolysis, myelotoxicity, respiratory depression, gastrointestinal bleeding, nephrotoxicity) has increased from 17 to 43 , representing an average rate of increase exceeding 6 drugs per year. This increase is a result of the introduction of new chemical entities and formulations.

This review identifies the key scientific concepts and clinical implications of grapefruitdrug interactions relevant to medical practice. We focus on grapefruit because it is the most widely examined, but other citrus fruits may have similar consequences. It was recently found that grapefruit and certain other citrus juices act by an additional mechanism to cause diminished systemic concentration of certain drugs by inhibiting drug transporters. ${ }^{4}$ However, we will focus on the most well-known and well-studied interaction: that of interference in the activity of the cytochrome P450 3A4 (CYP3A4) enzyme. A summary of the evidence used in this review, which comes mainly from randomized controlled trials, is found in Box 1.

\section{What are the key scientific concepts of grapefruit-drug interactions?}

The actions of drugs are terminated through several biological mechanisms. The most important is drug metabolism involving oxidation by enzymes belonging to the cytochrome $\mathrm{P} 450$ superfamily. Cytochrome P450 3A4 is particularly essential, because it is involved in the bioinactivation of about $50 \%$ of all drugs. ${ }^{5}$ CYP3A4 4 is located in epithelial cells (enterocytes) lining the small intestines and colon, and in the parenchymal cells of the liver (hepatocytes) (Figure 1). Consequently, orally administered drugs can be metabolized twice before reaching the systemic circulation. Thus, the percentage of drug absorbed unchanged (oral bioavailability) can be markedly attenuated. For example, the oral bioavailability of the antihypertensive drug felodipine is normally reduced to $15 \%$ of the oral dose. ${ }^{6}$ In other words, felodipine has low innate bioavailability. For this reason, it is subject to a potentially dramatic increase in systemic exposure and associated higher risk of overdose with grapefruit as a result of diminished CYP3A4 activity, primarily in the small intestine rather than in the liver.

The chemicals in grapefruit involved in this interaction are the furanocoumarins. ${ }^{7}$ Furanocoumarins are metabolized by CYP3A4 to reactive intermediates that bond covalently to the active site of the enzyme, causing irreversible inactivation (mechanism-based inhibition) ${ }^{8}$ Con-
Competing interests: None declared.

This article has been peer reviewed

Correspondence to:

David G. Bailey, david.bailey@1hsc.on.ca

CMAJ 2013. DOI:10.1503 /cmaj.120951

\section{KEY POINTS}

- Currently, more than 85 drugs have the possibility of interacting with grapefruit; of these drugs, 43 have interactions that can result in serious adverse effects.

- Drugs that interact with grapefruit have all of the following characteristics: they are administered orally, they have very low to intermediate absolute bioavailability, and they are metabolized by the cytochrome P450 3A4 enzyme (CYP3A4).

- All sources of grapefruit and certain related citrus fruits can irreversibly inhibit CYP3A4 in the gastrointestinal tract; to prevent this interaction, affected drugs should not be consumed with any of these fruits during the treatment period, or noninteracting alternative medications should be prescribed.

- Older patients have the greatest possibility of ingesting grapefruit and interacting medications and are the most vulnerable to the adverse clinical consequences. 
sequently, CYP3A4 activity in the small intestine is impaired until de novo synthesis returns the enzyme to its previous level. This mechanism explains the important clinical effects on drug pharmacokinetics, specifically the peak plasma drug concentration $\left(C_{\max }\right)$ and the area under the drug concentration-time curve (AUC). These key parameters of oral bioavailability are increased, whereas systemic elimination half-life is unaltered. The pharmacokinetics of intravenously administered drugs are unchanged. ${ }^{9,10}$

Because these chemicals are innate to grapefruit, all forms of the fruit (freshly squeezed juice, frozen concentrate and whole fruit) have the potential to reduce the activity of CYP3A4. One whole grapefruit or $200 \mathrm{~mL}$ of grapefruit juice is sufficient to cause clinically relevant increased systemic drug concentration and subsequent adverse effects. ${ }^{11,12}$ Seville oranges, (often used in marmalades), limes and pomelos also produce this interaction. ${ }^{13-15}$ Varieties of sweet orange, such as navel or valencia, do not contain furanocoumarins and do not produce this interaction. ${ }^{2}$

\section{What determines which drugs are affected?}

The interaction between medications and grapefruit is drug-specific and is not a class effect. Medications currently documented or predicted to have augmented oral bioavailability with grapefruit are shown in Table 1 and Appendix 1 (available at www.cmaj.ca/lookup/suppl/doi:10. 1503/cmaj.120951/-/DC1). Affected drugs possess 3 essential characteristics: they have an oral route of administration, they have very low $(<10 \%)$ to intermediate $(>30 \%-70 \%)$ intrinsic oral bioavailability, and they are metabolized by CYP3A4. These criteria can often be found in the product monograph or prescribing information (under "clinical pharmacology") for a drug,

\section{Box 1: Evidence used in this review}

We conducted a comprehensive search of the PubMed database for all available scientifically valid evidence using the keyword "grapefruit" and the following additional terms: "drug," "drug interaction," "pharmacokinetics," "cytochrome P450," "CYP3A4," "case report" or "review." In addition, we obtained product monographs and prescribing information for drugs recently introduced (i.e., in the last $4 \mathrm{yr}$ ) to the Canadian market. We assessed the following sections of these documents for relevant information: "Summary Product Information," "Warnings and Precautions," "Contraindications," "Adverse Reactions," "Drug Interactions" and "Action and Clinical Pharmacology." We identified 190 relevant publications (161 articles from PubMed; 29 product monographs or prescribing information sheets). Most of the information was from randomized controlled clinical trials $(n=102)$. The measured outcome from these studies was change in drug pharmacokinetics, and this was used to assess the potential for adverse clinical consequences. particularly for recently marketed drugs, and enable the prediction of whether an interaction might occur. In principle, this would assist practitioners in formulating appropriate management strategies without exposing patients to potentially harmful combinations.

\section{What determines the clinical significance of the interaction?}

The clinical significance of any particular interaction depends on the seriousness of the doserelated drug toxicity and the extent to which the systemic drug concentration increases. The latter relies on multiple factors that include the innate oral bioavailability of the interacting drug, the circumstances under which the grapefruit or other citrus fruit is consumed and the vulnerability of the patient to the interaction.

\section{Oral bioavailability}

The lower innate oral bioavailability of the drug, the greater the possible increase in systemic drug concentration. Grapefruit-interacting drugs can be separated into the 4 categories of very low $(<10 \%)$, low $(10 \%-30 \%)$, intermediate $(>30 \%$ $70 \%)$ and high $(>70 \%)$ absolute bioavailability. Drugs with very low bioavailability are the most likely to interact with grapefruit in a way that substantially alters their pharmacokinetics (i.e., analogous to consuming many doses of the drug alone). Conversely, drugs with high bioavailability have a marginally clinically relevant increase in systemic drug concentration.

\section{Circumstances of grapefruit consumption}

Although some pharmacokinetic studies have tested a higher than usual amount of grapefruit juice to determine the maximum effect, this should not be interpreted to mean that a relevant pharmacokinetic interaction will only occur with high levels of consumption. Indeed, a single usual amount (i.e., $200-250 \mathrm{~mL}$ juice or a whole grapefruit) has sufficient potency to cause a pertinent pharmacokinetic interaction. ${ }^{8,11,12}$ For example, felodipine combined with such a quantity of grapefruit had an average systemic drug concentration that was 3fold that seen with water. ${ }^{8,11}$ With twice the amount of grapefruit, there was only a modestly greater increase in the systemic concentration of felodipine, showing that a near-maximal pharmacokinetic interaction had already occurred with the consumption of the single quantity. ${ }^{11}$ With repeated ingestion of grapefruit ( $250 \mathrm{~mL}$ of juice, 3 times/d for $6 \mathrm{~d}$ ), a single dose of felodipine increased to 5 times the systemic concentration seen with water, suggesting that frequent consumption of a usual 
quantity daily augmented the pharmacokinetic effect moreso than the lone quantity. ${ }^{8}$

The interval between the ingestion of grapefruit and the adminstration of the interacting drug has some effect on pharmacokinetics. For example, a single glass $(200 \mathrm{~mL})$ of grapefruit juice ingested within 4 hours before felodipine produced the maximal pharmacokinetic interaction. ${ }^{16}$ Thereafter, an increased interval between ingesting the 2 substances slowly decreased the size of the effect - an interval of 10 hours produced an effect that was $50 \%$ of the maximum, and an interval of 24 hours produced an effect that was $25 \%$ of the maximum. ${ }^{16}$ Thus, a modest solitary quantity of grapefruit can have sufficient duration of action to affect interacting drugs that are administered once daily at any time during the dosing interval. Furthermore, repeated ingestion of grapefruit ( $200 \mathrm{~mL}$ of juice, 3 times/d for $7 \mathrm{~d}$ ) doubled the size of the interaction for 24 hours, consistent with a cumulative inhibitory action. ${ }^{17}$

Theoretically, the batch, type (i.e., white or pink) and storage conditions of grapefruit could possibly influence the size of the interaction. However, to our knowledge, these aspects have not been systematically studied.

\section{Patient vulnerability}

Patient vulnerability to this pharmacokinetic interaction varies markedly. For example, individ- ual systemic felodipine concentrations with a single serving of grapefruit juice $(250 \mathrm{~mL})$ ranged from 0 to 8 -fold that seen with water. ${ }^{8}$ Individual biopsies of the small intestine showed that higher CYP3A4 levels before ingesting grapefruit juice resulted in greater decrease in enzyme levels and greater increase in oral drug bioavailability after consumption of the juice. Accordingly, patients with elevated levels of CYP3A4 in the small intestine appear to be at increased risk for this interaction. It is impractical to routinely determine enterocyte CYP3A4 content in clinical practice. However, patients with substantial intestinal levels of CYP3A4 could require a higher dose of a grapefruit-interactive drug to achieve adequate systemic concentration. Thus, this is a possible means of identifying patients at greater risk before exposure to an interacting combination for medications routinely titrated to therapeutic effect.

Despite current science from well-conducted clinical studies, there remains the key practical issue of the frequency of adverse outcomes from this interaction occurring in routine clinical practice. Because multiple factors likely need to combine to achieve a marked increase in systemic drug concentration, it is reasonable to state that just exposure to any interacting combination would not be sufficient to elicit a clinically important change in drug response in all, if

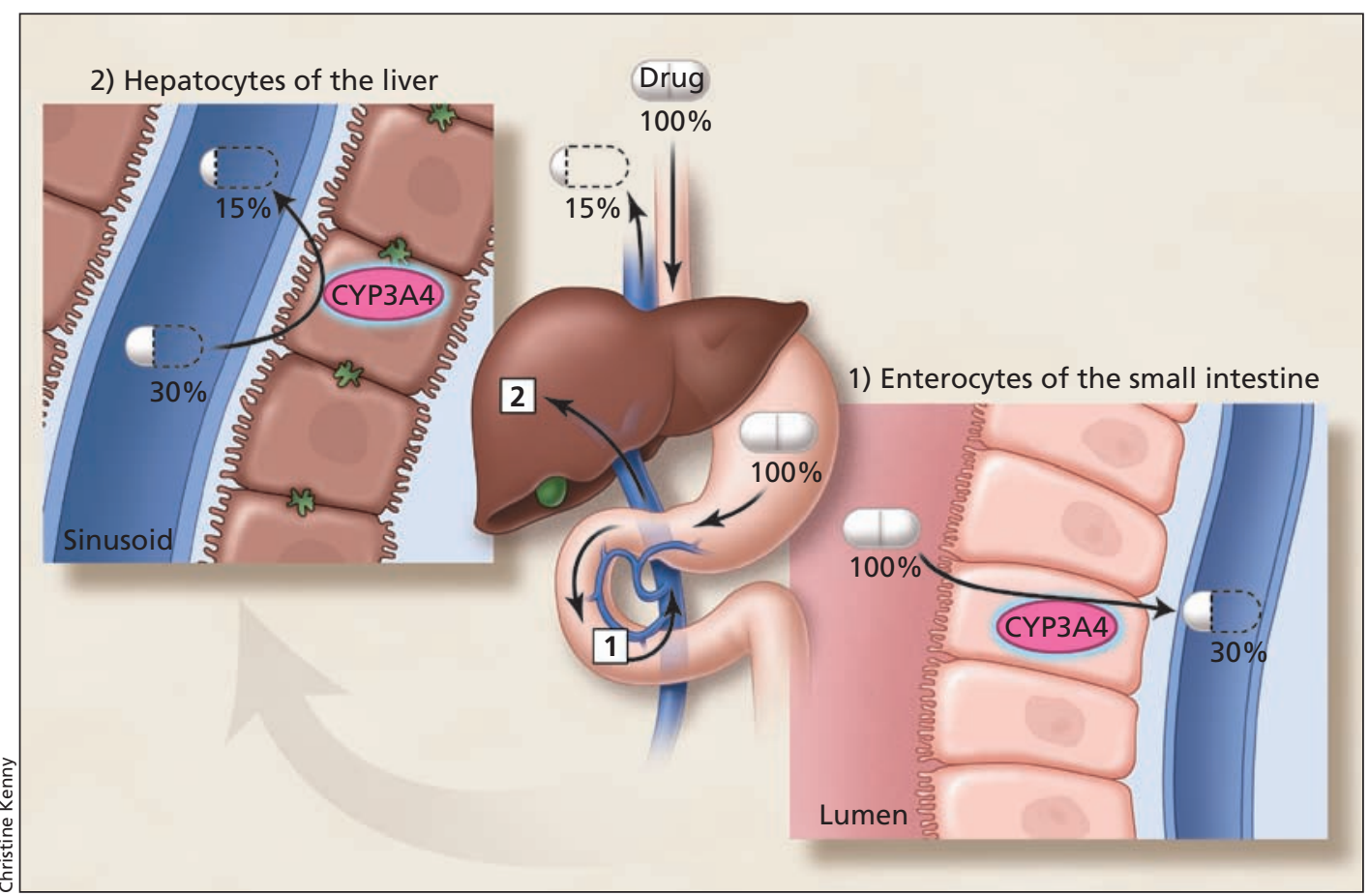

Figure 1: Sequential first-pass elimination of a drug, such as felodipine, through metabolism in enterocytes of the small intestine, then hepatocytes of the liver. The percentages of the initial dose that are available before and after passage through the gut wall and liver are shown. Although felodipine is $100 \%$ absorbed from the gastrointestinal tract, its bioavailability is only $15 \%$ after oral administration. CYP3A4 = cytochrome P450 enzyme 3A4. 
not most, cases. However, important toxic events have been documented for grapefruitdrug interactions (Table 2). ${ }^{18-26}$ These case reports uniformly cited the circumstance of a patient whose therapeutic dose of a susceptible drug was stabilized, who subsequently showed serious toxicity that occurred after several days of simultaneous intake of the drug and grapefruit in a normal or high quantity.

But how big a problem are such interactions? Unless health care professionals are aware of the possibility that the adverse event they are seeing might have an origin in the recent addition of grapefruit to the patient's diet, it is very unlikely

Table 1 (part 1 of 2): Selected drugs that interact with grapefruit, associated oral bioavailability, adverse event(s), predicted risk and possible alternative agents

\begin{tabular}{|c|c|c|c|c|}
\hline Interacting drugs & $\begin{array}{c}\text { Innate oral } \\
\text { bioavailability* }\end{array}$ & Dose-related adverse event(s) & $\begin{array}{c}\text { Predicted } \\
\text { interaction risk } \dagger\end{array}$ & $\begin{array}{c}\text { Potential alternative } \\
\text { agent(s) } \ddagger\end{array}$ \\
\hline \multicolumn{5}{|c|}{ Anticancer agents } \\
\hline Crizotinib & Intermediate & $\begin{array}{l}\text { Torsade de pointes, } \\
\text { myelotoxicity }\end{array}$ & High & \\
\hline Dasatinib & Not known & $\begin{array}{l}\text { Torsade de pointes, } \\
\text { myelotoxicity }\end{array}$ & High & Imatinib \\
\hline Erlotinib & Intermediate & Myelotoxicity & High & \\
\hline Everolimus & Low & Myelotoxicity, nephrotoxicity & High & \\
\hline Lapatinib & Incomplete & $\begin{array}{l}\text { Torsade de pointes, } \\
\text { myelotoxicity }\end{array}$ & High & \\
\hline Nilotinib & Intermediate & $\begin{array}{l}\text { Torsade de pointes, } \\
\text { myelotoxicity }\end{array}$ & High & Imatinib \\
\hline Pazopanib & Incomplete & $\begin{array}{l}\text { Torsade de pointes, } \\
\text { myelotoxicity }\end{array}$ & High & Sorafenib \\
\hline Sunitinib & Not known & $\begin{array}{l}\text { Torsade de pointes, } \\
\text { myelotoxicity }\end{array}$ & High & Sorafenib \\
\hline Vandetanib & Not known & $\begin{array}{l}\text { Torsade de pointes, } \\
\text { myelotoxicity }\end{array}$ & High & \\
\hline Venurafenib & Not known & $\begin{array}{l}\text { Torsade de pointes, } \\
\text { myelotoxicity }\end{array}$ & High & \\
\hline \multicolumn{5}{|c|}{ Anti-infective agents } \\
\hline Erythromycin & Intermediate & Torsade de pointes & High & Clarithromycin \\
\hline Halofantrine & Low & Torsade de pointes & Very high & Doxycycline \\
\hline Maraviroc & Low & Postural hypotension, syncope & Very high & Enfuvirtide \\
\hline Primaquine & Intermediate & Myelotoxicity & High & Doxycycline \\
\hline Quinine & Intermediate & Torsade de pointes & High & Doxycycline \\
\hline Rilpivirine & Not known & Torsade de pointes & High & Nevirapine \\
\hline \multicolumn{5}{|c|}{ Antilipemic agents } \\
\hline Atorvastatin & Low & Rhabdomyolysis & High & $\begin{array}{l}\text { Pravastatin, rosuvastatin, } \\
\text { fluvastatin }\end{array}$ \\
\hline Lovastatin & Very low & Rhabdomyolysis & Very high & $\begin{array}{l}\text { Pravastatin, rosuvastatin, } \\
\text { fluvastatin }\end{array}$ \\
\hline Simvastatin & Very low & Rhabdomyolysis & Very high & $\begin{array}{l}\text { Pravastatin, rosuvastatin, } \\
\text { fluvastatin }\end{array}$ \\
\hline \multicolumn{5}{|c|}{ Cardiovascular agents } \\
\hline Amiodarone & Intermediate & Torsade de pointes & High & Sotalol \\
\hline Apixaban & Intermediate & GI bleeding & High & Warfarin \\
\hline Clopidogrel & Very low & Loss of efficacy & High & Acetylsalicylic acid \\
\hline Dronedarone & Low & Torsade de pointes & Very high & Sotalol \\
\hline Eplerenone & Intermediate & $\begin{array}{l}\text { Hyperkalemia, serious } \\
\text { arrhythmias }\end{array}$ & High & Spironolactone \\
\hline Felodipine & Low & $\begin{array}{l}\text { Hypotension, peripheral } \\
\text { edema }\end{array}$ & Intermediate & Amlodipine \\
\hline Nifedipine & Intermediate & $\begin{array}{l}\text { Hypotension, peripheral } \\
\text { edema }\end{array}$ & Intermediate & Amlodipine \\
\hline
\end{tabular}


that they will investigate it. In addition, the patient may not volunteer this information. Thus, we contend that there remains a lack of knowledge about this interaction in the general health care community. Consequently, current data are not available to provide an absolute or even approximate number representing the true incidence of grapefruit-drug interactions in routine practice. Nonetheless, there are certain situations in which this interaction has a predictably greater likelihood of producing particularly adverse clinical results.

Table 1 (part 2 of 2): Selected drugs that interact with grapefruit, associated oral bioavailability, adverse event(s), predicted risk and possible alternative agents

\begin{tabular}{|c|c|c|c|c|}
\hline Interacting drugs & $\begin{array}{c}\text { Innate oral } \\
\text { bioavailability* }\end{array}$ & Dose-related adverse event(s) & $\begin{array}{c}\text { Predicted } \\
\text { interaction risk } \dagger\end{array}$ & $\begin{array}{c}\text { Potential alternative } \\
\text { agent(s) } \neq\end{array}$ \\
\hline \multicolumn{5}{|c|}{$\begin{array}{l}\text { Cardiovascular agents } \\
\text { (continued) }\end{array}$} \\
\hline Quinidine & High & Torsade de pointes & Intermediate & \\
\hline Rivaroxaban & High & GI bleeding & Intermediate & Warfarin \\
\hline Ticagrelor & Intermediate & Gl or kidney bleeding & High & Acetylsalicyclic acid \\
\hline \multicolumn{5}{|l|}{ CNS agents } \\
\hline Alfentanil (oral) & Intermediate & Respiratory depression & High & Hydromorphone, morphine \\
\hline Buspirone & Very low & Dizziness, sedation & High & Oxazepam, tamazepam \\
\hline Dextromethorphan & Very low & Hallucinations, somnolence & High & \\
\hline Fentanyl (oral) & Intermediate & Respiratory depression & High & Hydromorphone, morphine \\
\hline Ketamine (oral) & Low & Respiratory depression & Very high & Hydromorphone, morphine \\
\hline Lurasidone & Low & $\begin{array}{l}\text { Torsade de pointes, } \\
\text { orthostatic hypotension, } \\
\text { syncope }\end{array}$ & Very high & $\begin{array}{l}\text { Haloperidol, risperidone } \\
\text { olanzapine }\end{array}$ \\
\hline Oxycodone & Intermediate & Respiratory depression & High & Hydromorphone, morphine \\
\hline Pimozide & Intermediate & Torsade de pointes & High & $\begin{array}{l}\text { Haloperidol, risperidone, } \\
\text { olanzapine }\end{array}$ \\
\hline Quetiapine & Very low & Dizziness, somnolence & High & $\begin{array}{l}\text { Haloperidol, risperidone, } \\
\text { olanzapine }\end{array}$ \\
\hline Triazolam & Intermediate & Sedation & Intermediate & Alprazolam, lorazepam \\
\hline Ziprasidone & Intermediate & Torsade de pointes & High & $\begin{array}{l}\text { Haloperidol, risperidone } \\
\text { olanzapine }\end{array}$ \\
\hline \multicolumn{5}{|c|}{ Gastrointestinal agents } \\
\hline Domperidone & Low & Torsade de pointes & Very high & Metoclopramide \\
\hline \multicolumn{5}{|c|}{ Immunosuppressants } \\
\hline Cyclosporine & Low & Nephrotoxicity & High & \\
\hline Everolimus & Low & Myelotoxicity, nephrotoxicity & High & \\
\hline Sirolimus & Low & Myelotoxicity, nephrotoxicity & High & \\
\hline Tacrolimus & Low & Nephrotoxicity & High & \\
\hline \multicolumn{5}{|c|}{ Urinary tract agents } \\
\hline Darifenacin & Low & $\begin{array}{l}\text { Urinary retention, } \\
\text { constipation }\end{array}$ & Intermediate & \\
\hline Fesoterodine & Intermediate & $\begin{array}{l}\text { Urinary retention, } \\
\text { constipation }\end{array}$ & Intermediate & \\
\hline Solifenacin & High & Torsade de pointes & Intermediate & \\
\hline Silodosin & Intermediate & $\begin{array}{l}\text { Postural hypotension, } \\
\text { dizziness }\end{array}$ & Intermediate & \\
\hline Tamsulosin & Intermediate & $\begin{array}{l}\text { Postural hypotension, } \\
\text { dizziness }\end{array}$ & Intermediate & \\
\hline \multicolumn{5}{|c|}{$\begin{array}{l}\text { Note: CNS = central nervous system, GI = gastrointestinal. } \\
\text { *Population average: very low }<10 \% \text {, low }>10 \%-30 \% \text {, intermediate }>30 \%-70 \% \text {, high }>70 \% \text {. } \\
\text { tBased on the seriousness of the adverse effect and adjusted for the innate oral bioavailability of the drug, which is used to determine the potential increase in } \\
\text { systemic drug concentration. For older patients, particularly the elderly, it is recommended that grapefruit or other citrus fruits be contraindicated for drugs in the } \\
\text { very high or high category, or that a suggested alternative noninteracting drug be employed when available. } \\
\text { tCommonly prescribed drugs (Top } 100 \text { prescribed in } 2011 \text { in Canada) with the same therapeutic indication that have no or minor pharmacokinetic interaction with } \\
\text { grapefruit or other citrus fruits. }\end{array}$} \\
\hline
\end{tabular}




\section{Who is at higher risk of grapefruit-drug interactions?}

Although patient vulnerability is largely unknown, people older than 45 years are the prime purchasers of grapefruit and receive the most prescriptions for drugs..$^{27,28}$ Because of the size of this population, substantial exposure to this interaction is likely. In addition, a pronounced pharmacokinetic interaction has been shown to occur in patients older than 70 years. $^{29}$ Furthermore, older adults can have decreased capacity to compensate for excessive systemic drug concentrations. For example, felodipine (which normally lowers blood pressure) does not cause a compensating increase in heart rate in older adults when ingested with grapefruit, but does in young and middle-aged people, likely because of attenuated baroreceptor sensitivity associated with age. ${ }^{29}$ Consequently, older people appear to be an especially vulnerable population for grapefruitdrug interactions.

The predicted interaction risk for grapefruitinteracting drugs (Table 1, Appendix 1) (i.e., very high, high, intermediate, low) can assist clinicians in prescribing drugs for vulnerable patients and determining whether grapefruit or other citrus fruits should be contraindicated during pharmacotherapy, or whether an alternative therapy can be used.

\section{What are examples of important grapefruit-drug interactions?}

Examples of grapefruit-drug interactions were selected to illustrate documented pharmacoki-

\begin{tabular}{|c|c|c|}
\hline $\begin{array}{l}\text { Serious adverse } \\
\text { event }\end{array}$ & Drug & Amount of grapefruit consumed \\
\hline \multirow{2}{*}{$\begin{array}{l}\text { Torsade de } \\
\text { pointes }\end{array}$} & Amiodarone $^{18}$ & Juice, $1-1.5 \mathrm{~L} / \mathrm{d}$ on a regular basis \\
\hline & $\begin{array}{l}\text { Quinine in tonic } \\
\text { water }^{19}\end{array}$ & $\begin{array}{l}\text { Juice, high volume during } \\
\text { preceding days }\end{array}$ \\
\hline $\begin{array}{l}\text { Complete heart } \\
\text { block }\end{array}$ & Verapamil $^{20}$ & $\begin{array}{l}\text { Juice, high volume during } \\
\text { preceding days }\end{array}$ \\
\hline \multirow[t]{2}{*}{ Rhabdomyolysis } & Atorvastatin ${ }^{21,22}$ & $\begin{array}{l}\text { Juice, } 1-2 \text { glasses/d for } 5 d \text {; juice } \\
\text { from fresh grapefruit daily for } \\
2 \text { mo }\end{array}$ \\
\hline & Simvastatin $^{23}$ & Whole fruit, 1 fruit/d for 2 wk \\
\hline Nephrotoxicity & Tacrolimus $^{24}$ & $\begin{array}{l}\text { Marmalade, } 1.5 \mathrm{~kg} \text { eaten during } \\
\text { preceding } 1 \mathrm{wk}\end{array}$ \\
\hline Myelotoxicity & Colchicine $^{25}$ & Juice, 1 L/d for preceding 2 mo \\
\hline $\begin{array}{l}\text { Venous } \\
\text { thrombosis }\end{array}$ & Ethinylestradiol ${ }^{26}$ & $\begin{array}{l}\text { Whole fruit, } 1 \text { fruit/d for breakfast } \\
\text { for preceding } 3 d\end{array}$ \\
\hline
\end{tabular}

netic changes for which clinical outcomes are considered serious. These effects include torsade de pointes, rhabdomyolysis, nephrotoxicity and breast cancer.

\section{Torsade de pointes}

Torsade de pointes and risk of sudden death can occur with excessive prolongation of the corrected QT interval. The antiarrhythmic agent amiodarone had a mean $C_{\max }$ with grapefruit juice $(300 \mathrm{~mL}$ at 0 , 3 and $9 \mathrm{~h}$ relative to drug administration) corresponding to $180 \%$ of that with water; the AUC was $150 \%$ of that with water. ${ }^{30}$ The combination was also reported to markedly prolong the corrected QT interval and to cause ventricular arrhythmias, including torsade de pointes, in clinical practice..$^{18}$ Dronedarone, the chemical analog of amiodarone, was associated with reports of ventricular arrhythmia, cardiac arrest and torsade de pointes in clinical practice. ${ }^{31}$ Dronedarone with grapefruit juice (300 $\mathrm{mL}, 3$ times/d) resulted in a systemic drug concentration that was $300 \%$ of that of a control. ${ }^{32}$

Torsade de pointes can also occur with certain anticancer agents. The tyrosine kinase inhibitor nilotinib had a mean $C_{\max }$ with a single glass of grapefruit juice $(480 \mathrm{~mL})$ that was $160 \%$ of that with water, and an AUC that was $129 \%$ of that with water. ${ }^{33}$ Sunitinib, another tyrosine kinase inhibitor, had a mean bioavailability with grapefruit consumption (200 mL, 3 times/d for $3 \mathrm{~d}$ ) that was $111 \%$ of that compared with the level seen when grapefruit is not consumed. ${ }^{34}$ Although the pharmacokinetic interaction was weaker with sunitinib, the potential seriousness of the adverse effect and concern for interpatient variability would still warrant the avoidance of grapefruit.

\section{Rhabdomyolysis}

Rhabdomyolysis is the consequence of profound damage to skeletal muscle tissue, the release of large quantities of proteins, such as myoglobin, into the blood and acute renal failure. The active forms of all statins can produce this toxicity at excessive systemic concentrations. ${ }^{35}$

Simvastatin with grapefruit juice at high volume ( $400 \mathrm{~mL}, 3$ times/d for $3 \mathrm{~d}$ ) had an AUC that was $700 \%$ of that for water; at a more usual amount of juice $(200 \mathrm{~mL}$, once daily for $3 \mathrm{~d})$, the AUC was $330 \%$ of that with water. ${ }^{36,37}$ Rhabdomyolysis was also reported after 10 days concomitant consumption of fresh grapefruit. ${ }^{23}$ Lovastatin with grapefruit juice at a high level of consumption ( $400 \mathrm{~mL}, 3$ times/d for $3 \mathrm{~d}$ ) caused an AUC that was $500 \%$ of that with water. ${ }^{38}$ Atorvastatin, the most frequently prescribed drug in Canada in 2011, had an AUC with grapefruit juice $(250-400 \mathrm{~mL}, 3$ times/d for $2-4 \mathrm{~d}$ ) that ranged from $180 \%$ to $250 \%$ of that with water. ${ }^{39-41}$ 
Rhabdomyolysis has also been reported with grapefruit ingested at usual amounts ( Table 2). ${ }^{21-23}$ Thus, this adverse outcome with certain statins can occur with the ingestion of much less grapefruit than was previously expressed by the US Food and Drug Administration. ${ }^{42}$

However, taking atorvastatin in the evening and drinking grapefruit juice in the morning $(300 \mathrm{~mL} / \mathrm{d}$ from a specific lot prepared by the Florida Department of Citrus) resulted in drug serum concentrations that were $119 \%-126 \%$ of those seen with no consumption of grapefruit, with no evidence of skeletal muscle toxicity (e.g., elevated creatine phosphokinase, myalgia). ${ }^{43}$ In addition, pravastatin does not produce a pharmacokinetic interaction with grapefruit, ${ }^{39,40}$ rosuvastatin is eliminated unchanged, ${ }^{35}$ and fluvastatin is metabolized by an enzyme (cytochrome P450 2C9) that is not affected by grapefruit. ${ }^{35}$ Although staggering the ingestion of atorvastatin and grapefruit may reduce risk, substituting pravastatin, rosuvastatin or fluvastatin, or eliminating grapefruit juice from the diet, appears more preferable.

\section{Nephrotoxicity}

Nephrotoxicity can occur with the calcineurin inhibitors cyclosporine and tacrolimus, which are vital in preventing organ rejection after transplantation. Both of these drugs have a narrow range of therapeutic blood concentrations (i.e., below which they lack sufficient efficacy and above which they cause toxicity). Cyclosporine with grapefruit juice (single serving of $250 \mathrm{~mL}$ ) produced a mean oral bioavailability that was $162 \%$ of that with water. ${ }^{10}$ One of the 9 patients involved in this study had systemic drug availability increased to $670 \%$. In addition, a case report showed cyclosporine concentration to be increased to $600 \%$ with grapefruit. ${ }^{44}$ Taking tacrolimus after ingesting grapefruit juice $(250 \mathrm{~mL}, 4$ times/d for $3 \mathrm{~d})$ resulted in a $1000 \%$ higher trough blood concentration, causing profound inhibition of calcineurin phosphatase in a recipient of a liver transplant. ${ }^{45}$ Moreover, taking tacrolimus after consuming a large amount of grapefruit marmalade during the previous week caused a $500 \%$ greater blood concentration of the drug and acute renal dysfunction. ${ }^{24}$

\section{Breast cancer}

Based on increased oral bioavailability of estrogens (ethinylestradiol and 17- $\beta$-estradiol) with grapefruit juice, 2 large epidemiologic studies assessed the risk of breast cancer. ${ }^{46,47}$ The initial investigation found higher risk (relative risk $1.30,95 \%$ confidence interval 1.06-1.58) in women postmenopause who were taking estrogens and consuming one-quarter grapefruit or more per day compared with women not eating grapefruit. ${ }^{48}$ However, a follow-up study involving the same population found no such association. ${ }^{49}$ Thus, there is controversy over the risk of breast cancer in women postmenopause receiving estrogen therapy and consuming grapefruit.

\section{Gaps in knowledge}

Although much effort has been expended to provide a complete list of currently known and predicted drugs that will interact with grapefruit, the absence of a drug from Table 1 and Appendix 1 should not be interpreted to mean that it lacks this interaction. The few case reports presented in this review should not be considered as a useful index of the frequency of occurrence of serious grapefruit-drug interactions in general practice, as these are likely underreported.

\section{Conclusion}

Grapefruit and certain other citrus fruits represent examples of foods generally considered to be healthful, but with the potential for a pharmacokinetic interaction causing greatly enhanced oral drug bioavailability. The current trend of increasing numbers of newly marketed grapefruit-affected drugs possessing substantial adverse clinical effects necessitates an understanding of this interaction and the application of this knowledge for the safe and effective use of drugs in general practice.

\section{References}

1. Bailey DG, Spence JD, Edgar B, et al. Ethanol enhances the hemodynamic effects of felodipine. Clin Invest Med 1989;12:357-62.

2. Bailey DG, Arnold JMO, Spence JD. Grapefruit juice-drug interactions. Br J Clin Pharmacol 1998;46:101-10.

3. Bailey DG, Spence JD, Munoz C, et al. Interaction of citru juices with felodipine and nifedipine. Lancet 1991;337:268-9.

4. Bailey DG. Fruit juice inhibition of uptake transport: a new type of food-drug interaction. Br J Clin Pharmacol 2010;70:645-55.

5. Wilkinson GR. Drug metabolism and variability among patients in drug response. N Engl J Med 2005;352:2211-21.

6. Edgar B, Regardh CG, Johnsson G, et al. Felodipine kinetics in healthy man. Clin Pharmacol Ther 1985;38:205-11.

7. Guo LQ, Yamazoe Y. Inhibition of cytochrome P450 by furanocoumarins in grapefruit juice and herbal medicines. Acta Pharmacol Sin 2004;25:129-36

8. Lown KS, Bailey DG, Fontana RJ, et al. Grapefruit juice increases felodipine oral availability in humans by decreasing intestinal CYP3A protein expression. J Clin Invest 1997;99:2545-53.

9. Lundahl J, Regardh CG, Edgar B, et al. Effects of grapefruit juice ingestion - pharmacokinetics and haemodynamics of intravenously and orally administered felodipine in healthy men. Eur J Clin Pharmacol 1997;52:139-45.

10. Ducharme MP, Warbasse LH, Edwards DJ. Disposition of intravenous and oral cyclosporine after administration with grapefruit juice. Clin Pharmacol Ther 1995;57:485-91

11. Edgar B, Bailey D, Bergstrand R, et al. Acute effects of drinking grapefruit juice on the pharmacokinetics and dynamics of felodipine and its potential clinical relevance. Eur J Clin Pharmacol 1992;42: 313-7.

12. Bailey DG, Dresser GK, Kreeft JH, et al. Grapefruit-felodipine interaction: effect of unprocessed fruit and probable active ingredients. Clin Pharmacol Ther 2000;68:468-77.

13. Malhotra S, Bailey DG, Paine MF, et al. Seville orange juicefelodipine interaction: comparison with dilute grapefruit juice and involvement of the furanocoumarins. Clin Pharmacol Ther 2001;69:14-23. 
14. Bailey DG, Dresser GK, Bend JR. Bergamottin, lime juice and red wine as inhibitors of CYP3A4 activity: comparison with grapefruit juice. Clin Pharmacol Ther 2003;73:529-37.

15. Guo LQ, Chen QY, Wang X, et al. Different roles of pummelo furanocoumarin and cytochrome $\mathrm{P} 4503 \mathrm{~A} 5 * 3$ polymorphism in the fate and action of felodipine. Curr Drug Metab 2007;8:623-30.

16. Lundahl J, Regardh CG, Edgar B, et al. Relationship between time of intake of grapefruit juice and its effect on pharmacokinetics and pharmacodynamics of felodipine in healthy subjects. Eur J Clin Pharmacol 1995;49:61-7.

17. Takanaga H, Ohnishi A, Murakami H, et al. Relationship between time after intake of grapefruit juice and the effect on the pharmacokinetics and pharmacodynamics of nisoldipine in healthy subjects. Clin Pharmacol Ther 2000;67:201-14.

18. Agosti S, Casalino L, Bertero G, et al. A dangerous fruit juice. Am J Emerg Med 2012;30:248.e5-248.e8.

19. Hermans K, Stockman D, Van den Branden F. Grapefruit and tonic: a deadly combination in a patient with the long QT syndrome. Am J Med 2003;114:511-2.

20. Pillai U, Muzaffar J, Sen S, et al. Grapefruit juice and verapamil: a toxic cocktail. South Med J 2009;102:308-9.

21. Mazokopakis EE. Unusual causes of rhabdomyolysis. Intern Med J 2008:38:364-7.

22. Karch AM. The grapefruit challenge: the juice inhibits a crucial enzyme, with possibly fatal consequences. Am J Nurs 2004;104: 33-5.

23. Dreier JP, Endres M. Statin-associated rhabdomyolysis triggered by grapefruit consumption. Neurology 2004;62:670

24. Peynaud D, Charpiat B, Vial T, et al. Tacrolimus severe overdosage after intake of masked grapefruit in orange marmalade. Eur J Clin Pharmacol 2007;63:721-2.

25. Goldbart A, Press J, Sofer S, et al. Near fatal acute colchicine intoxication in a child. A case report. Eur J Pediatr 2000;159:895-7.

26. Grande LA, Mendez RD, Krug RT, et al. Attention grapefruit! Lancet 2009;373:1222.

27. Johannot L, Somerset SM. Age-related variations in flavonoid intake and sources in the Australian population. Public Health Nutr 2006;9:1045-54

28. Genser D. Food and drug interaction: consequences for the nutrition/health status. Ann Nutr Metab 2008;52(Suppl 1):29-32.

29. Dresser GK, Bailey DG, Carruthers SG. Grapefruit juice-felodipine interaction in the elderly. Clin Pharmacol Ther 2000;68:28-34.

30. Libersa CC, Brique SA, Motte KB, et al. Dramatic inhibition of amiodarone metabolism induced by grapefruit juice. $\mathrm{Br}$ J Clin Pharmacol 2000;49:373-8.

31. Kao DP, Hiatt WR, Krantz MJ. Proarrhythmic potential of dronedarone: emerging evidence from spontaneous adverse event reporting. Pharmacotherapy 2012 June 28 [Epub ahead of print].

32. Multaq (dronedarone $\mathrm{HCl}$ ) [product monograph]. Laval (QC); Sanofi-Aventis; 2009.

33. Yin OQ, Gallagher N, Li A, et al. Effect of grapefruit juice on the pharmacokinetics of nilotinib in healthy participants. J Clin Pharmacol 2010;50:188-94.

34. van Erp NP, Baker SD, Zandvliet AS, et al. Marginal increase of sunitinib exposure by grapefruit juice. Cancer Chemother Pharmacol 2011;67:695-703.

35. Neuvonen PJ, Niemi M, Backman JT. Drug interactions with lipid-lowering drugs: mechanisms and clinical relevance. Clin Pharmacol Ther 2006;80:565-81.

36. Lilja JJ, Kivisto KT, Neuvonen PJ. Grapefruit juice-simvastatin interaction: effect on serum concentrations of simvastatin, simvastatin acid, and HMG-CoA reductase inhibitors. Clin Pharmacol Ther 1998;64:477-83.

37. Lilja JJ, Neuvonen M, Neuvonen PJ. Effects of regular consumption of grapefruit juice on the pharmacokinetics of simvastatin. Br J Clin Pharmacol 2004;58:56-60.

38. Kantola T, Kivisto KT, Neuvonen PJ. Grapefruit juice greatly increases serum concentrations of lovastatin and lovastatin acid. Clin Pharmacol Ther 1998;63:397-402.

39. Lilja JJ, Kivisto KT, Neuvonen PJ. Grapefruit juice increases serum concentrations of atorvastatin and has no effect on pravastatin. Clin Pharmacol Ther 1999;66:118-27.

40. Ando H, Tsuruoka S, Yanagihara H, et al. Effects of grapefruit juice on the pharmacokinetics of pitavastatin and atorvastatin. $B r$ J Clin Pharmacol 2005;60:494-7.

41. Fukazawa I, Uchida N, Uchida E, et al. Effects of grapefruit juice pharmacokinetics of atorvastatin and pravastatin in Japanese. Br J Clin Pharmacol 2004;57:448-55.

42. Lipid-altering agents (also called statins). Avoid food-drug interactions: a guide from the National Consumers League and U.S. Food and Drug Administration. Publication no. (FDA) CDER 101933. p 13. Available: www.fda.gov/downloads/Drugs/Resources ForYou/Consumers/BuyingUsingMedicineSafely/EnsuringSafeUse ofMedicine/GeneralUseofMedicine/UCM229033.pdf (accessed 2012 Oct. 25)

43. Reddy P, Ellington D, Zhu Y, et al. Serum concentrations and clinical effects of atorvastatin in patients taking grapefruit juice daily. Br J Clin Pharmacol 2011;72:434-41.

44. Jürgen Roth H, Wintergalen M. Unusual high levels of ciclosporin in a female patient - the impact of lifestyle? Clin Lab 2005;51:425-7.

45. Fukatsu S, Fukudo M, Masuda S, et al. Delayed effect of grapefruit juice on pharmacokinetics and pharmacodynamics of tacrolimus in a living-donor liver transplant recipient. Drug Metab Pharmacokinet 2006;21:122-5.

46. Schubert W, Cullberg G, Edgar B, et al. Inhibition of $17 \beta$-estradiol metabolism by grapefruit juice in ovariectomized women. Maturitas 1994;20:155-63.

47. Weber A, Jäger R, Börner A, et al. Can grapefruit juice influence ethinylestradiol bioavailability? Contraception 1996;53: 41-7.

48. Monroe KR, Murphy SP, Kolonel LN, et al. Prospective study of grapefruit intake and risk of breast cancer in postmenopausal women: the Multiethnic Cohort Study. Br J Cancer 2007;97:440-5.

49. Spencer EA, Key TJ, Appleby PN, et al. Prospective study of the association between grapefruit intake and risk of breast cancer in the European Prospective Investigation into Cancer and Nutrition (EPIC). Cancer Causes Control 2009;20:803-9.

Affiliations: From the Lawson Health Research Institute (Bailey), London, Ont.; the Department of Medicine (Arnold, Dresser) and the Divisions of Cardiology (Arnold) and Clinical Pharmacology (Dresser), Western University, London, Ont.

Contributors: David Bailey drafted the manuscript for internal review and revision. George Dresser and Malcolm Arnold revised the article for important intellectual content. All of the authors approved the final version submitted for publication. 